\title{
The impact of facade materials on the thermal comfort and energy efficiency of offices buildings
}

\author{
Khadraoui M A ${ }^{1,}{ }^{*}$, Sriti L ${ }^{2}$, Besbas $\mathrm{S}^{1}$
}

\begin{abstract}
1 * Department of architecture, Mohamed Khider University, BP 145 RP 07000 Biskra, Algeria.
2 Laboratory of design and modeling of architectural ambiances and urban forms (LACOMOFA), Mohamed Khider University, BP 145 RP 07000 Biskra, Algeria.

* Corresponding Author: makhadraoui@yahoo.com
\end{abstract}

Received: 04-02-2018

Revised: 08-04-2018

Accepted: 16-04-2018

\begin{abstract}
In order to improve thermal comfort conditions of tertiary buildings through the facades of buildings, a research has been undertaken with the intention of developing a contextually appropriate and energetically efficient facade under the conditions of a hot and arid climate. The study has taken as its starting point the analysis of comfort conditions of a set of office buildings located in Biskra. These buildings were distinguished from standpoints of the treatment of their facades and the materials used. The study proposes to evaluate the thermal functioning of the different materials of the facade, then to optimize their behavior by acting on their material characteristics and the walls composition. The facade, indeed, represents a place of interaction and exchange between the inside and the outside, the performance of which is due to factors that are formal, material and technical. This article presents the main results of the analytical work. The investigation is based on an empirical approach (measurements in situ on real cases) as well as on a parametric simulation study. The results show that the facade represents with excellence the place of interaction and exchange between the interior and the exterior, the performance of which is due to factors that are both material and conceptual. Through a set of recommendations, this study tries to develop a material composition of high-performing facade that can respond optimally to the requirements of a tertiary building in a desert climate, while ensuring a pleasant thermal ambience and low consumption energy.
\end{abstract}

Key words: Facade, material characteristics, thermal comfort, offices, simulation.

\section{Introduction}

The use of energy has always been a fundamental mean for man to improve his comfort (Heiselberg, 2009; Seoud, 2012; Arnal, 2013). At the same time, the search for the control of thermal environments within the built environment, while minimizing energy consumption, continues to be considered as a challenge. The latter seems to be increasingly difficult to meet, especially with the current climatic and economic conditions in which the building represents an energy-intensive sector, responsible for increasing energy consumption. However, it is important not only to guarantee the quality of indoor environments, but also to minimize the amount of energy required for the operation of supplementary equipment (Cantin et al., 2005).

According to the APRUE report (2007), the tertiary and residential sector are considered in Algeria as energy intensive sectors, represents $41 \%$ of total consumption (Figure 1). Indeed, it alone holds a significant rate of energy consumption, a large quantity of which is used mainly to meet the needs of thermal comfort (heating and cooling). This situation is the result of the irrational indifferent choices to the context and neglecting the climatic specificities during the conception. 
Thermal comfort and energy efficiency are two crucial expectations for the building owner, with the development of technologies in the field of construction buildings, the building should also be undertaken under the sustainability concept (Matthew, 2010).

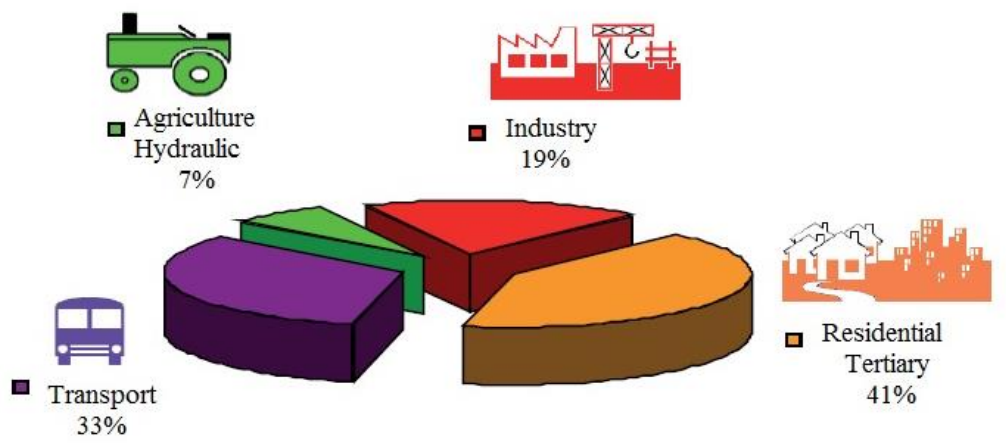

Fig 1. Final energy consumption in Algeria by sectors according to APRUE report.

\section{The thermal behavior of the facade materials}

The thermal behavior of a building is complex and depends on the stresses to which it is subjected, notably the temperature of the outside air. The judicious choice of building materials contributes to the reduction of ambient air temperatures inside the building (Mokhtari, 2008). The architecture should thus aim to integrate the climatic data of the site, to reduce energy consumption due to heating and cooling (Benhouhou, 2012). The building envelope must be selected according to the loads and dynamic environmental conditions outside and inside (Matthew, 2010). According to this research, it turns out that the choice of an envelope is a decisive decision in the architectural design given its complexity and its hyper-interfered aspects (Khadraoui et al., 2017), because the proper design can limit the thermal impacts and obviously the energy consumption (Giovanni et al., 2014).

Several studies have been carried out in order to optimize the thermal operation of the architectural envelope in a passive manner by acting on the vertical walls. The facade represents a separating shell that interacts between the interior space and the outside climatic conditions, its performance must be identical to that building. In this research, an attempt will be made to determine the impact of the material characteristics of the facade on the interior environment by taking measurements in situ as well as by parametric simulation.

\subsection{The empirical study}

This research was carried out on administrative buildings and more precisely on office buildings, distinguished by the nature of their envelope. The buildings studied represent the most recurrent and representative facade types in the city of Biskra (an Algerian town in the South), which were selected after a thorough analysis according to previously selected criteria and the assigned objectives; the latter has given us four typologies of façade (Figure 2).

Table 1 illustrates the composition of the facades in each case.

Table 1. The composition of the facades of the study cases.

\begin{tabular}{|c|c|c|}
\hline Study case & The composition of the facade from the outside to the inside & Thickness (cm) \\
\hline \hline B1 & $\begin{array}{c}\text { Ventilated facade in terracotta } 1.6 \mathrm{~cm} \text { - cavity of air - cement mortar } \\
2 \mathrm{~cm} \text { - brick 15cm - air 5cm - brick 10 cm - plaster mortar 2cm }\end{array}$ & 45 \\
\hline B2 & Curtain wall with single glazing & 1 \\
\hline B3 & Cement mortar 2,5cm - earthen brick of 45cm - plaster mortar 2,5cm & 50 \\
\hline B4 & $\begin{array}{r}\text { Double skin facade in steel - cavity of air - cement mortar 2cm - brick } \\
15 \mathrm{~cm} \text { - air 5 cm - brick 10 cm - plaster mortar 2cm }\end{array}$ & 70 \\
\hline
\end{tabular}




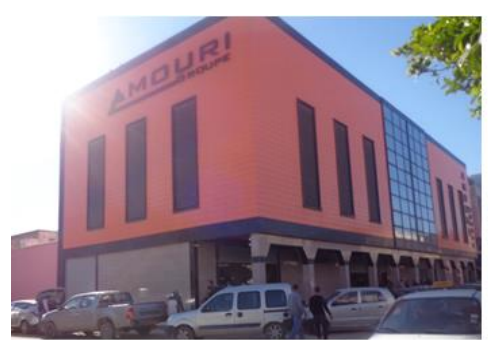

B1

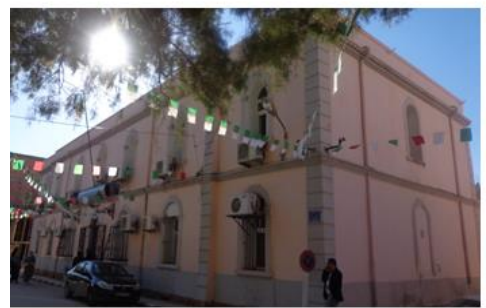

B3

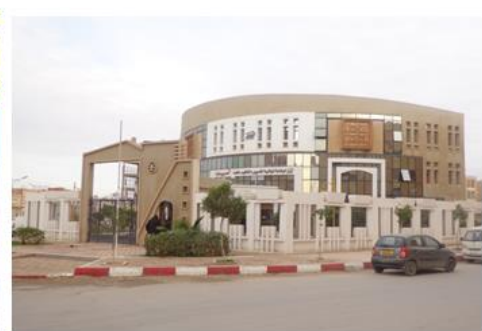

B2

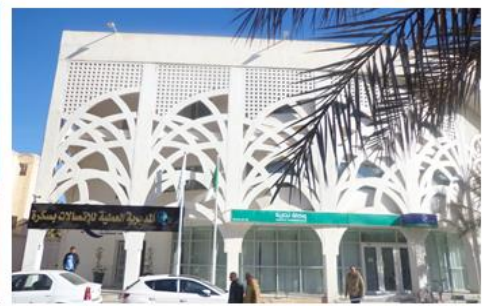

B4

Fig 2. Photos of study corpus.

Building B1: administrative group with a ventilated facade, the B2 is an administration with a curtain wall facade. The B3 is a colonial-era building with a terracotta wall and the B4 is a relatively new construction with a double-skinned steel façade.

The study context in the city of Biskra, which is located in the south of Algeria at a latitude of $34^{\circ}$ 48 'North and a longitude of $5^{\circ} 44^{\prime}$ East. It rises to an altitude of 86 meters. The average monthly temperature under shelter in the town of Biskra for about 15 years (between 2000 and 2015) illustrated in (Figure 3). Through the exploitation of the data of this graph, the coldest or the warmest period can be determined in order to calculate the "design day" and the "design week" of each period.

Biskra airport station

average monthly temperature under shelter

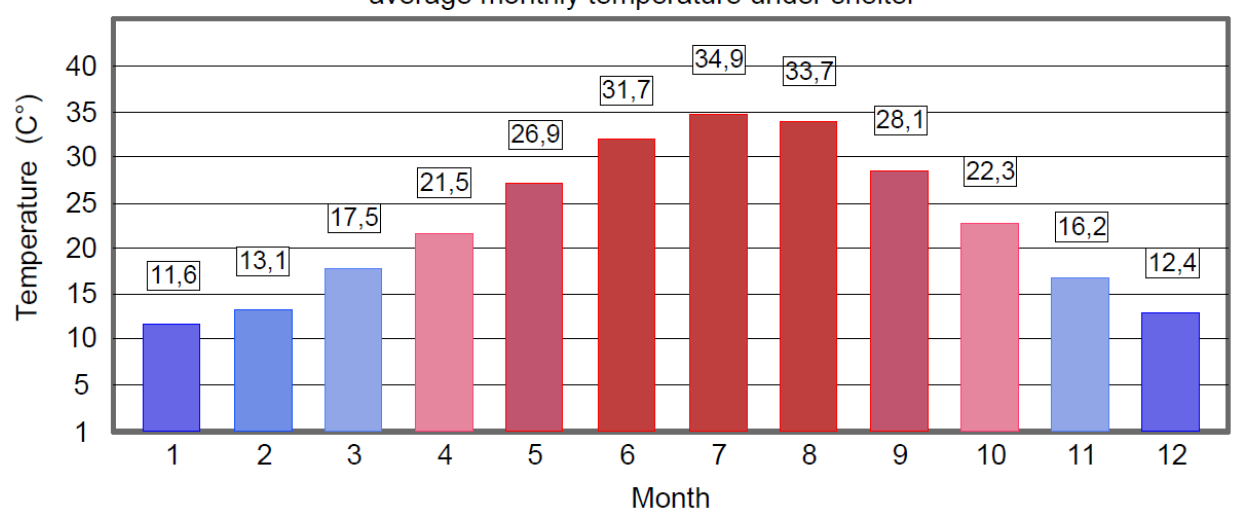

Fig 3. The average monthly temperature under cover of the city of Biskra (Biskra Weather Station, 2016).

The measurements were taken during the winter period (December 13-14th 2016 ) after the determination of the coldest week "design week" (Figure 4) that is relatively connected with period of 15 years. This temperature (Tout) was determined by the use of meteorological data and the calculation of the average daily temperature (Hong, 1999). 


\begin{tabular}{|c|c|c|c|c|c|c|c|c|c|c|c|c|c|c|c|c|c|}
\hline December & 2000 & 2001 & 2002 & 2003 & 2004 & 2005 & 2006 & 2007 & 2008 & 2009 & 2010 & 2011 & 2012 & 2013 & 2014 & 2015 & Average \\
\hline 1 & 15.4 & 17 & 14.8 & 13.2 & 15.4 & 11.7 & 16.4 & 14.3 & 12.7 & 12.7 & 22 & 15.4 & 7.3 & 10.5 & 13.9 & 14 & 14.17 \\
\hline 2 & 17.4 & 14.8 & 17.1 & 13.8 & 16 & 10.2 & 15.3 & 14.3 & 10.7 & 13.2 & 17.9 & 15.6 & 9.6 & 10.5 & 13.9 & 13.1 & 13.96 \\
\hline 3 & 16.4 & 14.2 & 15.3 & 13.8 & 16.6 & 10.7 & 13.3 & 13.5 & 11.4 & 11.9 & 15.5 & 17.1 & 11.5 & 11.6 & 17 & 11.7 & 13.84 \\
\hline 4 & 14.2 & 13.9 & 14.2 & 10 & 17 & 12.1 & 14.5 & 15.8 & 10.6 & 13.6 & 12.2 & 16.1 & 11.5 & 14 & 12.7 & 13.9 & 13.52 \\
\hline 5 & 13.5 & 15.3 & 14.9 & 11 & 17 & 12.9 & 15.8 & 16.2 & 9.1 & 15.8 & 9.2 & 15.2 & 13.6 & 16.3 & 13.5 & 11.8 & 13.82 \\
\hline 6 & 12.9 & 15.2 & 10.8 & 13.7 & 14.1 & 14.5 & 13.2 & 16 & 16 & 14.5 & 11.1 & 14.7 & 13.4 & 13.5 & 15.2 & 14.1 & 13.93 \\
\hline 7 & 13 & 15.6 & 13.9 & 14.5 & 14.2 & 13.8 & 15.3 & 15.5 & 14.2 & 13.5 & 12.8 & 17 & 11 & 13.2 & 12.3 & 13.5 & 13.96 \\
\hline 8 & 13.6 & 13 & 12.6 & 15.9 & 14.1 & 12.4 & 13.7 & 17 & 12.5 & 13.7 & 16.1 & 18.5 & 14.7 & 11.3 & 14.9 & 14.1 & 14.26 \\
\hline 9 & 14.1 & 11.8 & 11.2 & 10.9 & 12.8 & 12.6 & 13.6 & 17.8 & 14.7 & 14.75 & 18 & 13 & 13 & 12.3 & 12.8 & 11 & 13.40 \\
\hline 10 & 18.4 & 11 & 11.2 & 8.8 & 14.3 & 11.3 & 12.8 & 17.3 & 12.4 & 16.5 & 20.2 & 12 & 9.5 & 13.8 & 13.7 & 13 & 13.51 \\
\hline 11 & 17.2 & 10.1 & 13.7 & 12.3 & 13.5 & 12.6 & 15.3 & 14 & 10.3 & 14.4 & 13.25 & 13.9 & 10.5 & 13.9 & 13.3 & 13.3 & 13.22 \\
\hline 12 & 14.6 & 7.6 & 14.7 & 15.2 & 15.5 & 9.7 & 15 & 11.9 & 9.2 & 13 & 8.7 & 13.2 & 10.5 & 12 & 15.1 & 11.6 & 12.34 \\
\hline 13 & 14.2 & 8.7 & 14.1 & 18.4 & 12.5 & 10 & 13.8 & 11.6 & 8.7 & 11 & 11.7 & 16 & 9.8 & 11.1 & 10.1 & 10 & 11.98 \\
\hline 14 & 13.4 & 10.1 & 14.3 & 15.1 & 12.8 & 14.3 & 13.5 & 12 & 6 & 12.5 & 15.2 & 12.4 & 12.3 & 11.2 & 8.9 & 12 & 12.25 \\
\hline 15 & 12.3 & 11.2 & 16.2 & 17.9 & 12.9 & 12.6 & 13.8 & 9.4 & 9.2 & 10.1 & 13.1 & 14.5 & 15.2 & 12.3 & 12.5 & 13.7 & 12.93 \\
\hline 16 & 13.3 & 11.7 & 14.4 & 14.5 & 13.7 & 12 & 14.2 & 6.9 & 7.2 & 10.8 & 8.9 & 13.8 & 15 & 11.3 & 10.6 & 15 & 12.08 \\
\hline 17 & 12.1 & 13.7 & 13.5 & 9.8 & 14.8 & 11.4 & 15 & 9.6 & 6.2 & 12.6 & 8.5 & 13.6 & 17.6 & 9.9 & 14.3 & 14.2 & 12.30 \\
\hline 18 & 12.2 & 7.7 & 13.2 & 11.7 & 14.6 & 13.6 & 15.7 & 5.9 & 10.4 & 15 & 9.2 & 13.3 & 17.3 & 11.2 & 14.1 & 13.5 & 12.41 \\
\hline 19 & 11 & 8.3 & 14.5 & 12 & 15.2 & 11.5 & 13 & 7.4 & 11.9 & 16 & 10.7 & 11.6 & 16.4 & 12.5 & 15.2 & 13 & 12.51 \\
\hline 20 & 11.3 & 10.4 & 15.5 & 13.7 & 13.3 & 11.2 & 12.7 & 8.1 & 14.2 & 13.2 & 15.2 & 10.3 & 14.5 & 11 & 16.3 & 13.7 & 12.79 \\
\hline 21 & 14.2 & 11.4 & 16.9 & 14 & 14 & 13 & 11.8 & 10.8 & 14.1 & 9.1 & 13.6 & 12.9 & 16.8 & 16.3 & 15.7 & 13.4 & 13.63 \\
\hline 22 & 13 & 11.6 & 15.6 & 11 & 12 & 10.4 & 12.1 & 16.1 & 12 & 11 & 15.1 & 17.2 & 19.2 & 16.2 & 12.9 & 14 & 13.71 \\
\hline 23 & 14.5 & 10.6 & 13.7 & 10.7 & 11.5 & 10 & 10.9 & 14.9 & 12 & 13.3 & 18.1 & 16.4 & 14.7 & 15.9 & 12 & 14.2 & 13.34 \\
\hline 24 & 10.9 & 10.7 & 15.6 & 10.6 & 9.2 & 8.3 & 8.8 & 13.7 & 10.7 & 16.1 & 14.4 & 14 & 13.7 & 14.2 & 11.6 & 11.2 & 12.11 \\
\hline 25 & 11.2 & 10.6 & 17.7 & 12.5 & 6.3 & 7.5 & 14.9 & 15.3 & 10.2 & 18.9 & 10.5 & 13 & 12.8 & 11 & 11.7 & 12.3 & 12.28 \\
\hline 26 & 11.3 & 11.8 & 18.8 & 9.2 & 8.3 & 9.2 & 13.5 & 15.8 & 10.9 & 16.5 & 11 & 12.8 & 12.3 & 13.2 & 12.2 & 14.4 & 12.58 \\
\hline 27 & 13.9 & 12.1 & 13 & 6.4 & 6.6 & 10.4 & 13.8 & 15 & 10.6 & 16.3 & 10.2 & 11.3 & 16.4 & 13.2 & 14 & 13.5 & 12.29 \\
\hline 28 & 13.8 & 11.1 & 16.1 & 7.1 & 7 & 10.4 & 13.1 & 13.3 & 10.8 & 14 & 10.7 & 10.5 & 13.5 & 13.4 & 12.8 & 11.7 & 11.83 \\
\hline 29 & 15.6 & 8.8 & 15 & 13.5 & 8.8 & 12 & 10.5 & 12 & 14.7 & 15.1 & 9.1 & 11.6 & 14.7 & 12.8 & 13.6 & 9.7 & 12.34 \\
\hline 30 & 14.1 & 9.4 & 12.5 & 11.6 & 12 & 10.2 & 11.8 & 14.5 & 15 & 13.2 & 8.2 & 12.9 & 13.4 & 12 & 11.2 & 11.5 & 12.09 \\
\hline 31 & 11.3 & 10.6 & 13.2 & 13.7 & 12.3 & 9 & 12.5 & 13.6 & 13.1 & 11.4 & 10.5 & 13.3 & 13.1 & 10 & 9.7 & 13 & 11.89 \\
\hline
\end{tabular}

Fig 4. Design week determination

Bi-hourly measurements were made under natural conditions during the winter period (December 2016). The measured temperatures are the ambient inside temperature (Ta), the internal surface temperature (Tis) and the temperature outside (Tout). The instruments used are a "Testo 480 " thermometer and an infrared thermometer (Figure 5).

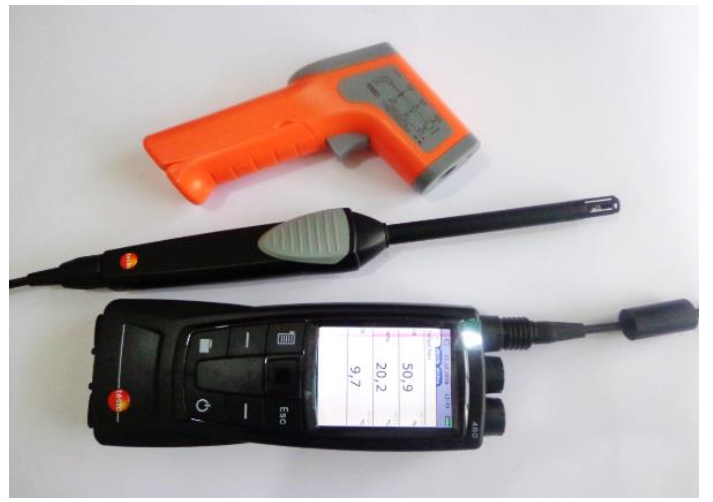

Fig 5. The instruments used for taking measurements.

We have measured the ambient temperature and the internal surface temperature, because in a simplified way the temperature of the comfort is calculated by the average of the temperature of the air and the surface temperature of the walls as shown by the formula (1) (Herde, 2005).

$T_{\text {comfort }}=\frac{T_{\text {Air }}+T_{\text {surface }}}{2}$

\subsection{Modeling and simulation of the thermal behavior of the facade}

In order to predict the problems of the building, simulation tools should be used, for example to design a high-performance envelope, it is necessary to make an appropriate numerical simulation (Tittelein, 2008; Matthew, 2010).

The simulation makes it possible to evaluate the thermal behavior of the facade throughout the year with the possibility of making corrections, therefore parametric improvements of elements with the possibility of determining the impact of each parameter.

Making a thorough rapid simulation of a design allows the architect to understand in a way the impacts of architectural choices and climate on the behavior of space. The simple action of testing a space using a design simulation creates an intuitive understanding of performance that 
can be used immediately; through subsequent design activities and future projects. While design simulation is often seen as a specialized engineer's tool to predict energy performance, the importance of this tool for architects is the freedom to play and develop ideas. Instead of applying the generic sustainable strategies that the architect does not fully understand, design simulation allows for a quick assessment of assigned objectives (Buratti et al., 2013; Anderson, 2014).

The software used is "Energyplus V8-4-0", "Open Studio V1-9-0" and "Sketchup 2015" (Figure6). The software "EnegyPlus" is used as a calculation engine, this tool has been validated and has shown its performance (Spitz, 2012; Soudani, 2016). The 3D model was modeled on Sketchup (graphical interface) and the "Open Studio" platform is used to link Sketchup to EnergyPlus. We have developed our own library of building materials and space use scenarios, while using the climate file of the city in question in "epw" format.

We have created a virtual model ( $\mathrm{Rm})$ as reference model, it is a small desk in rectangular form of $20 \mathrm{~m}^{2}(4 \mathrm{mx} 5 \mathrm{~m})$ with a height of $3 \mathrm{~m}$. It contains a single window oriented towards the South and occupies $12.6 \%$ of the facade.

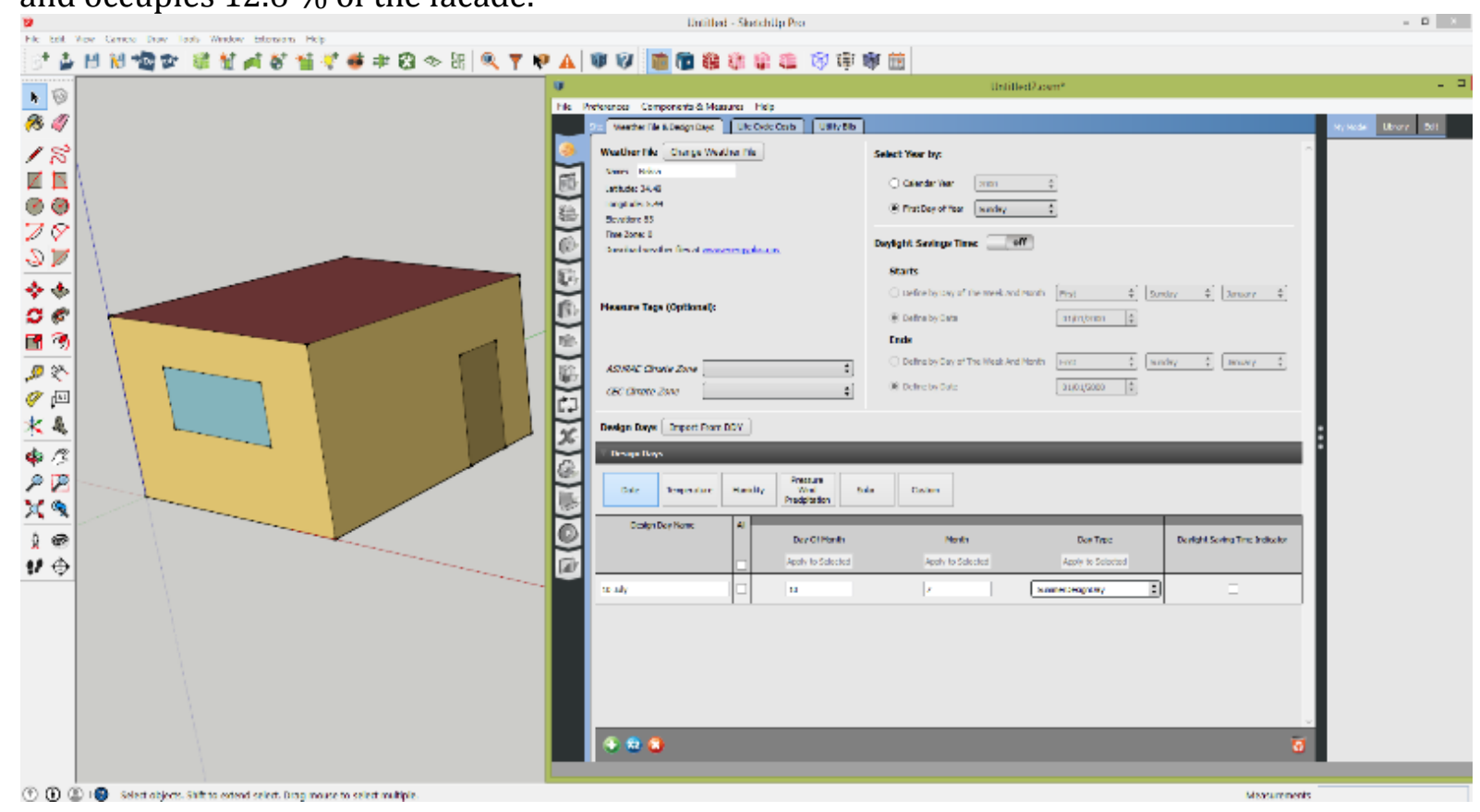

Fig 6. Sketchup-Open Studio-Energyplus simulation platform.

According to the analysis of real cases, we found a random use of building materials without any relation to the climate context of the city. In this sense, we have developed the reference model $(\mathrm{Rm})$ which reflects a simple case with the material composition that is used in this region. In the second step, we have created an Inertia model (Im) and tested the impact of thermal inertia by the use of heavy materials with high thermal inertia.

Table 2 illustrates the thermal characteristics of the materials of the model produced. The type of glazing used is a simple glazing.

Table 2. The composition of the facades of the study cases.

\begin{tabular}{|c|c|c|c|c|}
\hline Materials & $\lambda(\mathrm{W} / \mathrm{m} . \mathrm{k})$ & $\mathrm{C}(\mathrm{J} / \mathrm{kg} \cdot \mathrm{k})$ & $\mathrm{D}(\mathrm{Kg} / \mathrm{m} 3)$ & $\mathrm{T}(\mathrm{cm})$ \\
\hline \hline Cement- mortar & 0,80 & 850 & 1900 & 0,2 \\
\hline Hollow-Brick & 0,39 & 1000 & 650 & $10-15$ \\
\hline Plaster- mortar & 0,57 & 1008 & 1150 & 02 \\
\hline Air & 0,047 & 1000 & 1 & 05 \\
\hline Concrete & 1,75 & 1080 & 2500 & 10 \\
\hline
\end{tabular}




\section{Results and discussion}

The results obtained after determination of the design week of the city of Biskra.

\subsection{Discussion of the empirical study}

The graph (Figure 7) illustrates the measurements obtained for buildings B1 and B3. It reveals that the indoor temperature is almost stable throughout the day with maximum amplitude of 5.6 ${ }^{\circ} \mathrm{C}$ at $8 \mathrm{~h}$.

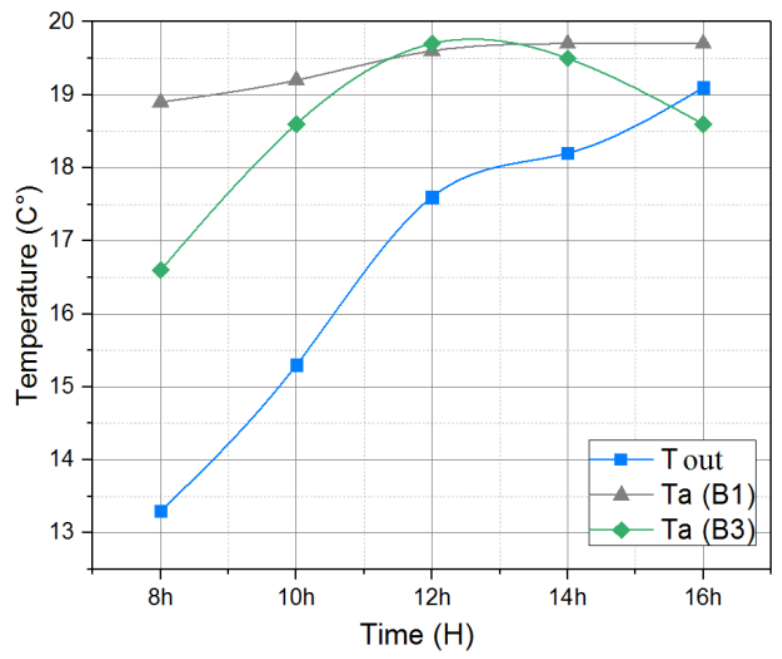

Fig 7. Graphs of the ambient temperatures measured in studied buildings B1 and B3.

The composition of the facades for B1 and B3 prevents temperature fluctuations and ensures an internal temperature varying between $16.6^{\circ} \mathrm{C}$ and $19.7^{\circ} \mathrm{C}$ during the working period. It is also noted that these temperatures are quite comfortable with respect to the outside temperature, which reaches a minimum of $13.3^{\circ} \mathrm{C}$ at $8 \mathrm{~h}$.

As for the graph (Figure 8), which summarizes the measurements obtained for buildings B2 and $\mathrm{B} 4$, it is noted that the temperature inside the premises is less stable in comparison with B1 and B3. The large glazed surfaces of the facades B2 and B4 have caused an excessive increase in temperature, but only after a time of exposure to solar radiation, which generates more heat inside and allows the vertical walls to behave like a greenhouse.

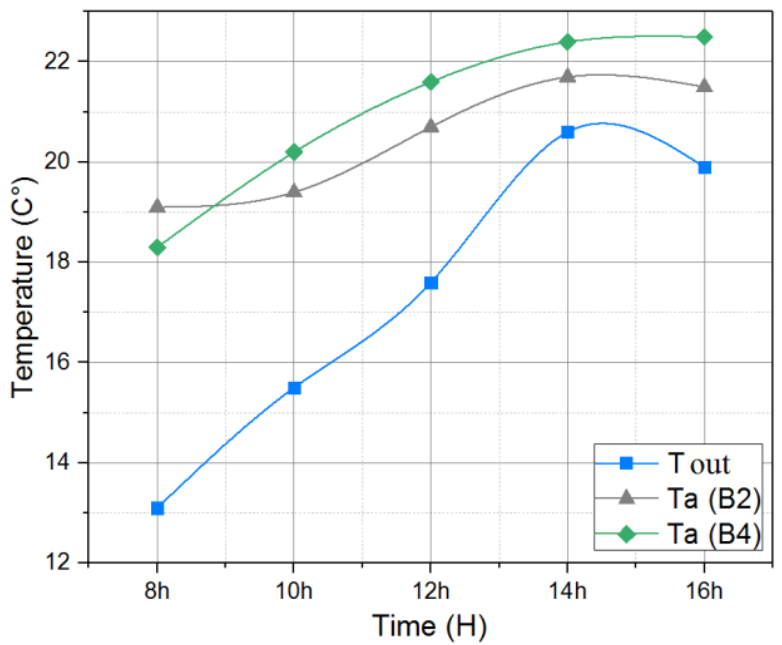

Fig 8. Graphs of the ambient temperatures measured in studied buildings B2 and B4. 
It is noted that the temperature at $10 \mathrm{~h}$ is in the order of $21.6^{\circ} \mathrm{C}$; it culminates at $16 \mathrm{~h}$ in $\mathrm{B} 4$ and reaches $22.4{ }^{\circ} \mathrm{C}$, which is considered as an annoying temperature (according to a personal observation and the opinion of the users).

Overall, it can be said that the best thermal behavior is that is in buildings B1 and B3, which ensures a stable temperature due to the material composition of the facade. Whereas the worst cases are respectively B2 and B4 where we found an excess of heat in a cold period.

Figure 9 shows the measurements recorded for the outdoor temperature (Tout) and the internal surface temperature (Tis) during the week design. It is found that B1 and B3, (Tis) is more stable unlike B2 and B4 where there is a significant increase in surface temperature. This is due to the physical characteristics of the materials composing if the facades, which are visibly climatically unsuitable (in B2 single glazing and in B4 double steel skin).
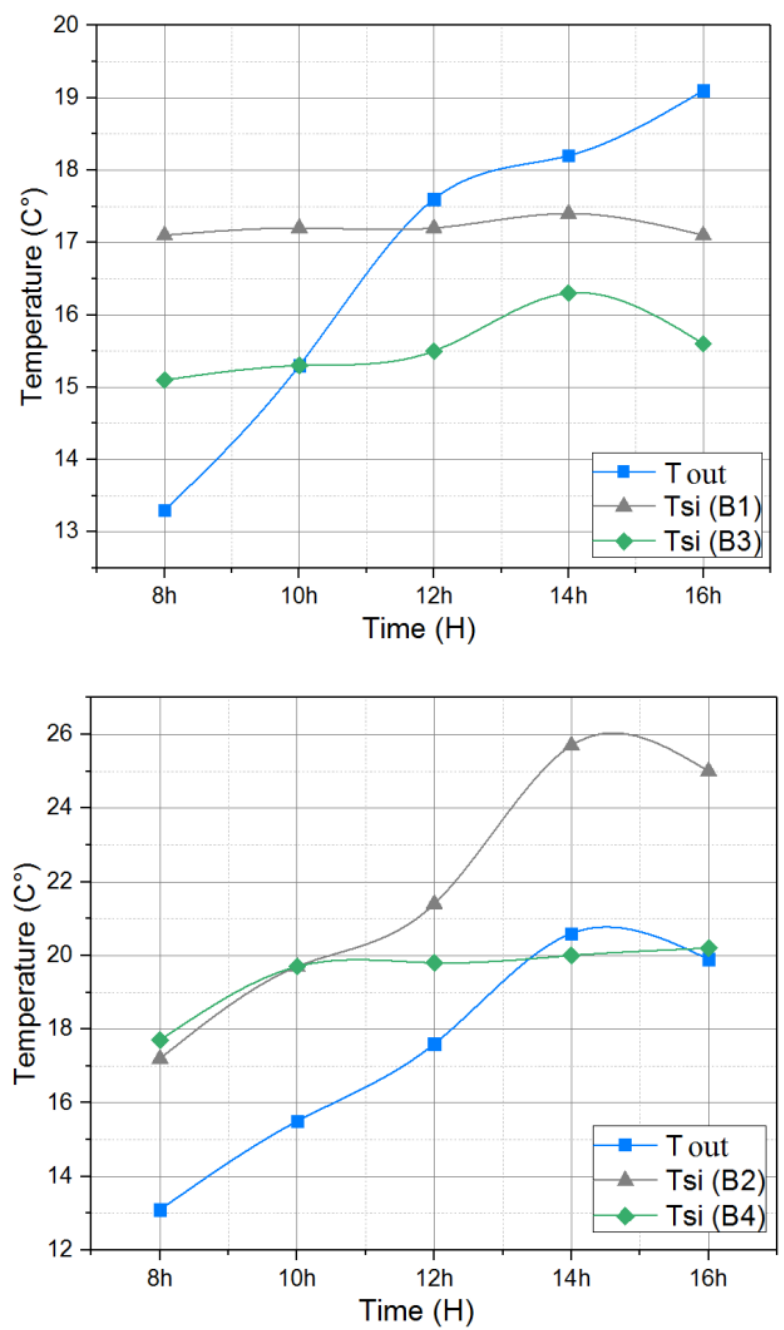

Fig 9. Graphs of the outside temperature and the surface temperatures measured in studied buildings.

Thus, the materials used in building B3 have an impact on the stability of the surface temperature, followed by the ventilated facade (VF) of B1. On the other hand, the glass facade of B2 and the double skin facade (DSF) of steel of B4 negatively influence their thermal behavior through an increase of (Tis).

\subsection{Results of the simulation}

Figure 10 shows the thermal amplitude between the outdoor temperature and the operational temperature (To) simulated with the reference model for one year and allows simultaneous 
viewing of the (isothermal) in order to determine the most unfavorable zone (overheating zones).

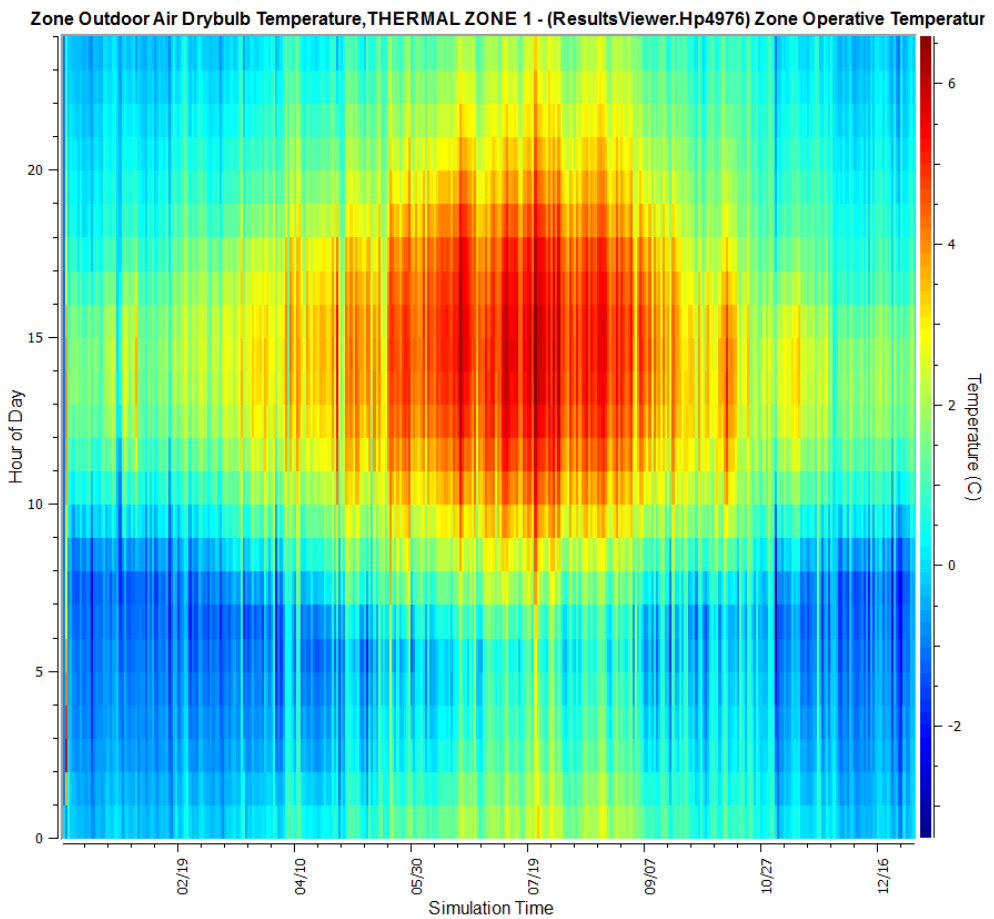

Fig 10. The thermal amplitude of the reference model.

During the winter, the thermal amplitude is in the order from $3.4{ }^{\circ} \mathrm{C}$ and during the summer, it reaches $6.6{ }^{\circ} \mathrm{C}$. The great amplitudes is during the summer period; where the maximum temperature can exceeds $40^{\circ} \mathrm{C}$ during the month of July.

The results of the thermal amplitude of the second model developed (inertia model "Im") are shown in (Figure 11).

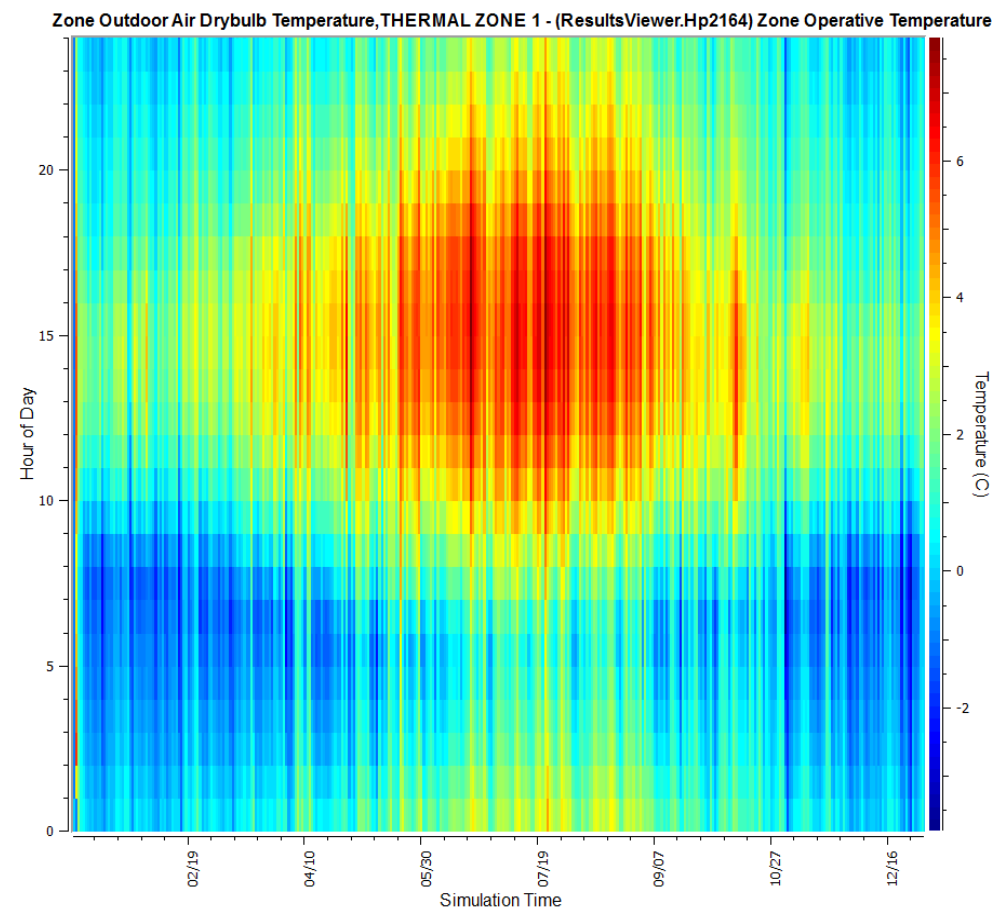

Fig 11. The thermal amplitude of the inertia model. 
It is noted that there is an improvement in this model compared to the previous model by increasing the values of the thermal amplitude, generally throughout the year and especially during the summer (from $6.6{ }^{\circ} \mathrm{C}$ to $7.8{ }^{\circ} \mathrm{C}$ ). Thus, it can be seen that the thermal inertia influences the improvement of the thermal comfort conditions in the spaces, through these characteristics of attenuation of the heat flux with a delay in time (the time of the phase shift), which ignores the sudden change of the temperature and ensures comfort to the space users.

Figure 12 illustrates the thermal amplitude of the two models studied during a hot day (July). Generally, it is noted that the best thermal behavior is the inertia model (Im) all day long, this decrease in temperature is mainly dependent on the material characteristics of the facade of the model (Im).

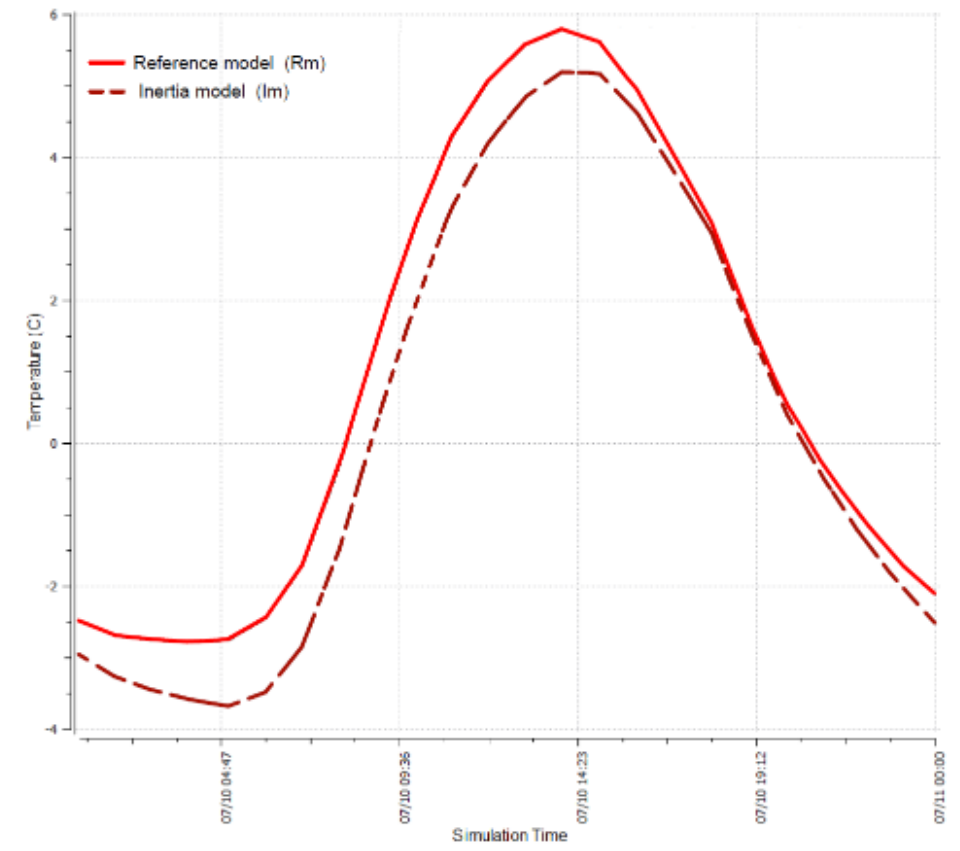

Fig 12. The thermal amplitude of the two models during a hot day.

The thermal characteristics of the heavy materials used in the (Im) facade have a major impact on the improvement of thermal conditions.

In a hot and arid climatic conditions, thermal inertia in particular plays an important role in ensuring hygrothermal equilibrium. In summer, it reduces thermal fluctuations and extreme temperatures. In winter, it avoids too sudden falls in temperature and highlights the optimal management of heat inputs (Medjelakh, 2008).

The analysis and comparison between the two simulated models asserts the important impact of the physical characteristics of the facade on the thermal behavior and energy efficiency of the building as well as the comfort of the users.

\section{Conclusions}

This article presents the main results obtained from a study based on an empirical investigation (measurements taken in situ in existing buildings) as well as a parametric analysis by simulation. The objective of the investigation is to evaluate the impact of the material and conceptual aspects of the facade on the thermal comfort of office spaces in a hot and arid climate.

The first part of the study is based on measurements confirmed the importance of mastering the physical characteristics of the building materials used on the facade. The importance of thermal inertia for a hot and arid climate and its impact on the thermal comfort was highlighted. The choice of building materials remains a determining factor in the thermal behavior of the facade. 
The second part of the study was carried out using a simulation with the "EnergyPlus" software using "Open Studio" as a platform. A parametric analysis was carried out and a preponderant factor of the thermal phenomena of the facade was studied (the thermal inertia). The results show that the increase in the thermal inertia of the facade materials has a positive influence on the thermal behavior of the building and the comfort of users of space.

The results of this research open several avenues for future investigation. Possibilities for studies and optimization related to the impact of the composition of the wall and the type of materials on thermal comfort and energy efficiency.

\section{References}

Anderson K. (2014). Design Energy Simulation for Architects, Routledge Publishing, First Ed., New York.

Arnal, E. (2013). Modélisation et commande hiérarchisées du bâtiment pour l'amélioration des performances énergétiques, thermiques et optiques, Doctoral thesis, The National Institute of Applied Sciences of Lyon, France.

APRUE, (2007). Rapport de la consommation énergétique finale de l'Algérie, Ministère de l'Energie et des Mines-Agence Nationale pour la Promotion et la Rationalisation de l'Utilisation de l'Energie.

Benhouhou, M.N., (2012). L'impact des matériaux sur le confort thermique dans les zones semi-arides, Memory of magister, EPAU, Algeria.

Buratti, C., Moretti, E., Belloni, E., \& Cotana, F. (2013). Unsteady simulation of energy performance and thermal comfort in non-residential buildings. Building and Environment, 59, 482-491.

Cantin, R., \& Guarracino, G., (2005). Complexité du confort thermique dans les bâtiments, VIème congrès Européen de Science des Systèmes, pp. 02-04.

Giovanni, Z., \& Andrea, F. (2014). Evolutionary Optimisation of Façade Design A New Approach for the Design of Building Envelopes, Springer, First Ed., London.

Heiselberg, P. (2009). Expert Guide-Part 1 Responsive Building Concepts, Université d'Aalborg, First Ed., Danemark.

Herde A., \& Liebard A. (2005). Traité d'architecture et d'urbanisme bioclimatiques, Le Moniteur et Observ'ER, $1^{\text {st }}$ Ed., France.

Hong, T., Chou, S. K., \& Bong, T. Y. (1999). A design day for building load and energy estimation. Building and Environment, 34(4), 469-477.

Khadraoui M.A., \& Sriti, L. (2017). Facades' thermal behavior of the office buildings in a hot and arid climate. Algerian Journal of Engineering Architecture and Urbanism, 1(2), 28-38.

Matthew, R.H. (2010). Materials for energy efficiency and thermal comfort in buildings, Woodhead Publishing, $1^{\text {st }}$ Ed., New Delhi.

Medjelakh, D., \& Abdou, S. (2008). Impact de l'inertie thermique sur le confort hygrothermique et la consommation énergétique du bâtiment. Revue des Energies Renouvelables, 11(3), 329-341.

Mokhtari, A., Brahimi, K., \& Benziada, R. (2008). Architecture et confort thermique dans les zones arides Application au cas de la ville de Béchar. Revue des énergies renouvelables, 11(2), 307-315.

Seoud, S. (2012). Audit énergétique de bâtiments tertiaires, Memory of magister, EPAU, Algeria.

Soudani, L.C.L. (2016). Modelling and experimental validation of the hygrothermal performances of earth as a building material. Doctoral thesis, University of Lyon, France.

Spitz, C., (2012). Analyse de la fiabilité des outils de simulation et des incertitudes de métrologie appliquée à l'efficacité énergétique des bâtiments, Doctoral thesis, University of Grenoble, France.

Tittelein, P. (2008). Environnements de simulation adaptés à l'étude du comportement énergétique des bâtiments basse consommation. Doctoral thesis, University of Savoy, France. 